Eixo Temático: Biologia Aplicada

\title{
ET-09-005 \\ PLANTAS ORNAMENTAIS DA FAMÍLIA APOCYNACEAE JUSS. NO JARDIM DO CAMPUS II DA UNIVERSIDADE DO ESTADO DA BAHIA (UNEB), ALAGOINHAS, BAHIA
}

Daniela Santos Souza Nascimentoํㅗㄹ Alexa Araújo de Oliveira Paes Coelho²

${ }^{1}$ Graduanda do Curso de Licenciatura em Ciências Biológicas da Universidade do Estado da Bahia (UNEB), Campus II. Alagoinhas-BA. Bolsista de Iniciação Científica da Fundação de Amparo à Pesquisa do Estado da Bahia (FAPESB).

${ }^{2}$ Professora Dra. da Universidade do Estado da Bahia (UNEB), Campus II. Alagoinhas-BA.

$$
\text { http://dx.doi.org/10.21472/congrebio2016.et-09-005 }
$$

\section{RESUMO}

A Família Apocynaceae Juss., está entre as dez maiores famílias em número de espécies em meio as angiospermas, com o centro de diversidade nos trópicos, amplamente distribuída em regiões tropicais e subtropicais. Bastante interessante do ponto de vista econômico, tem destaque para suas plantas ornamentais. São consideradas plantas ornamentais aquelas que chamam a atenção e despertam interesses por seus caracteres estéticos intrínsecos. Objetivou-se com o presente trabalho, realizar o levantamento florístico das espécies de plantas ornamentais pertencentes à Família Apocynaceae Juss. no Jardim do Campus II, da Universidade do Estado da Bahia (UNEB), contribuindo desta forma para o conhecimento dos exemplares amostrados. A coleta foi realizada no período de janeiro a março de 2016, no horário matutino, com auxílio de tesoura de poda, caderno de campo, máquina fotográfica para o registro dos exemplares em seus habitats, sacos plásticos para acondicionar o material botânico ornamental e, a utilização de literatura taxonômica especializada para a identificação dos exemplares. Foram registradas no Jardim do campus II da UNEB, 5 espécies de plantas ornamentais pertencentes a família botânica Apocynaceae Juss., distribuídas em 4 gêneros, Plumeria L., Allamanda L., Catharanthus G.Don e Thevetia L. Assim, o uso de espécies ornamentais serve não apenas para o embelezamento do campus, mas como fonte de material botânico para aulas práticas e pesquisas de graduação. (FAPESB).

Palavras-chave: Plantas ornamentais; Apocynaceae; Florística.

\section{INTRODUÇÃO}

A Família Apocynaceae Juss., está entre as dez maiores famílias em número de espécies em meio as angiospermas, com o centro de diversidade nos trópicos, amplamente distribuída em regiões tropicais e subtropicais (JUDD et al., 2009). Engloba de 250 a 550 gêneros e entre 3.700 e 5.100 espécies (RAPINI, 2000; JUDD et al., 2009).

Apocynaceae é reconhecida por apresentar em seu hábito árvores, arbustos e lianas, canais laticíferos, folhas geralmente opostas, inteiras ou menos frequente verticiladas, flores pentâmeras, folículos na maioria dos gêneros e sementes comosas (JUDD et al., 2000; RAPINI, 2000).

Bastante interessante do ponto de vista econômico, alguns representantes da família têm tido destaque pela utilidade fotoquímica, no fornecimento de glicosídeos cardiotônicos, alcalóides, antibióticos, bem como na produção e sucos, polpas, geleias e de madeiras, com ênfase também para suas plantas ornamentais (RIZZINI e MORS, 1995). 
São consideradas plantas ornamentais aquelas que chamam a atenção e despertam interesses por seus caracteres estéticos intrínsecos como cor, forma das folhas e flores, aspectos fenológicos, ou extrínsecos como a sombra projetada, o balançar causado pelo vento e ainda pela estrutura formada com a vizinhança, podendo ser usada na arquitetura e paisagismo de espaços externos (MELLO FILHO, 1986). É importante ressaltar que árvores também podem ser consideradas espécies ornamentais quando as mesmas forem implantadas com intuito de promover um maior embelezamento ao ambiente (SILVA, 2009).

Plantas ornamentais distinguem-se pelo florescimento, forma ou colorido das folhas e aspecto geral da planta. Os efeitos visuais que as plantas ornamentais podem produzir estão associados aos grupos ou tipos que elas pertencem (árvores, arbustos, trepadeiras, herbáceas) e aos atributos particulares de cada planta, tais como: o efeito das flores ou a folhagem vistosa (LORENZI e SOUZA, 2001).

Nas áreas urbanizadas a presença de vegetação oferece inúmeros benefícios à saúde física e mental da população tais como: melhoria da qualidade do ar, oferta de recursos alimentícios, bem estar psicológico; todos incrementando significativamente sua qualidade de vida (SALATINO, 2001).

\section{OBJETIVO}

O presente trabalho teve como objetivo, realizar o levantamento florístico das espécies de plantas ornamentais pertencentes a Família Apocynaceae Juss. no Jardim do Campus II da Universidade do Estado da Bahia - UNEB.

\section{METODOLOGIA}

O trabalho foi realizado na UNEB - Campus II, localizada na cidade Alagoinhas-Bahia. O Município de Alagoinhas, localizado no leste da Bahia está inserido na Bacia Sedimentar do Recôncavo Norte, entre as coordenadas $11^{\circ} 55^{\prime} 51^{\prime \prime}$ e $12^{\circ} 15^{\prime} 23^{\prime \prime}$ S e $38^{\circ} 15^{\prime} 00^{\prime}$ e $38^{\circ} 35^{\prime} 00^{\prime \prime}$ W. Localiza-se a $107 \mathrm{~km}$ da capital Salvador (SEI, 2010). Possui área de $1179 \mathrm{~km}^{2}$, correspondendo a 0,21\% da área do estado da Bahia.

É o município mais populoso e melhor urbanizado do território do Agreste de Alagoinhas/Litoral Norte, abrigando mais de um quarto da sua população com 142.160 habitantes. Sua área inclui os tipos climáticos: úmido e subúmido, com totais anuais de chuvas de $1.280 \mathrm{~mm}$ e temperatura média em torno de $24^{\circ} \mathrm{C}$ (SEI, 2010).

A coleta do material botânico ornamental foi realizada no período de janeiro a março de 2016, no horário matutino, com auxílio de tesoura de poda e caderneta de campo para anotar as informações sobre o material, e máquina fotográfica para o registro dos exemplares em seus habitats. Todo o material coletado foi acondicionado em saco plástico para posterior herborização e confecção de exsicatas. A identificação das espécies se deu por meio de análises morfológicas, com auxílio de chaves analíticas e literatura especializada. Os nomes científicos, bem como sua autoria, foram confirmados de acordo com a flora do Brasil (http://floradobrasil.jbrj.gov.br). Os exemplares amostrados foram organizados em tabela, onde foi elaborado uma listagem florística com o número de indivíduos, espécies, nome vulgar e quanto a origem (exótica ou nativa).

\section{RESULTADOS E DISCUSSÃO}

Foram registradas no Jardim do Campus II da Universidade do Estado da Bahia UNEB, 5 espécies de plantas ornamentais pertencentes a família botânica Apocynaceae Juss., distribuídas em 4 gêneros (tabela 1). O gênero mais representativo foi Plumeria L. com duas espécies; Plumeria pudica Jacq. e Plumeria rubra L. Os gêneros Allamanda L., Catharanthus G.Don e Thevetia L. tiveram uma espécie cada: Allamanda catártica L., Catharanthus roseus (L.) Don. e Thevetia peruviana V. Seh., respectivamente. 
As espécies de plantas ornamentais foram identificadas e classificadas quanto a origem 3 espécies são exóticas e 2 espécies nativas. Foi observado também o quantitativo da espécie Catharanthus roseus (L.) Don. no jardim, foi percebido que a espécie esteve presente mais vezes no jardim esse fato pode ser explicado pois, essa espécie de planta é muito rústica e pouco exigente, por esses motivos pode ser cultivada em quase todo o mundo onde se apresenta um clima tropical e subtropical, ocorrendo um processo de naturalização a estes novos lugares (LORENZI e SOUZA, 2001).Em contra partida a espécie Plumeria rubra L. foi encontrado apenas um exemplar no jardim, isso pode ser explicado por a espécie se tratar de uma árvore de médio porte cerca de 7 metros de altura exigindo assim um espaço maior no seu cultivo, então prefere-se um quantitativo menor dessa espécie no jardim. A figura 1 mostra as espécies de plantas ornamentais de Apocynaceae encontradas no Jardim do campus II da UNEB.

Tabela 1 - Lista de espécies de plantas ornamentais cultivadas no Jardim do Campus II UNEB com os respectivos nomes científicos, nomes vulgares e origem.

\begin{tabular}{|c|c|c|c|}
\hline Nome científico & $\begin{array}{l}\text { Número de } \\
\text { indivíduos }\end{array}$ & Nome vulgar & Origem \\
\hline Allamanda catártica L. & 5 & $\begin{array}{l}\text { Allamanda-da-flor-grande, } \\
\text { dedal. }\end{array}$ & Nativa. \\
\hline Catharanthus roseus (L.) Don. & 7 & Boa-noite, vinca. & Exótica \\
\hline Thevetia peruviana V. Seh. & 2 & $\begin{array}{l}\text { Chapéu-de-napoleão, jorro- } \\
\text { jorro. }\end{array}$ & Nativa \\
\hline Plumeria pudica Jacq. & 4 & $\begin{array}{l}\text { Jasmim-do-caribe, buquê-de- } \\
\text { noiva. }\end{array}$ & Exótica. \\
\hline Plumeria rubra L. & 1 & Jasmim-manga. & Exótica. \\
\hline
\end{tabular}


Figura 1. Lista de espécies de plantas ornamentais cultivadas no Jardim do Campus II - UNEB. A-B: Thevetia peruviana V. Seh.C-D: Allamanda catártica L. E-F: Catharanthus roseus (L.) Don. e G-H: Plumeria pudica Jacq.
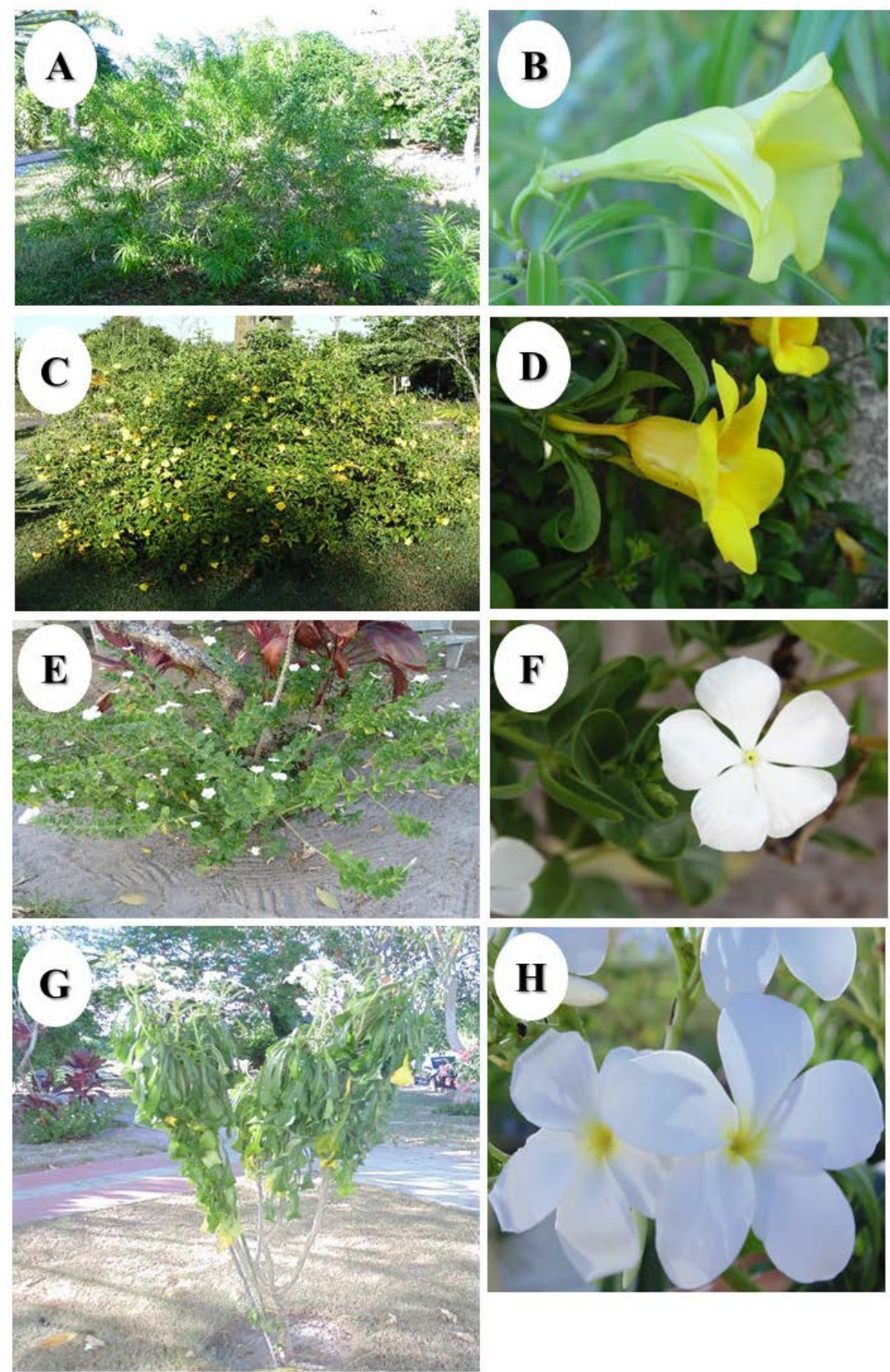

Segundo Melo et al. (2011) as plantas ornamentais são implantadas com o objetivo de proporcionar um prazer estético, porém elas desempenham inúmeras funções na paisagem. A imensa área foliar cria um elo entre as demais formas de vegetação, realçando a beleza, que age sobre o psíquico das pessoas que o observa, transmitindo a sensação de paz, conforto interior, 
tranquilidade, alegria, e harmonia, pois seus efeitos visuais fazem com que as pessoas se sintam mais à vontade nesses ambientes.

Ainda de acordo com o autor, elas nos fornecem a privacidade desejada, o frescor de uma sombra, a beleza das folhas e flores, barreira ao vento frio, pode suavizar o incessante barulho da cidade, dar deliciosos frutos e, além de tudo, ter importância ecológica fundamental na preservação da fauna e flora.

Na UNEB campus II, é comum o uso das plantas ornamentais em aulas práticas de botânica, onde se estudam as flores, os frutos, os tipos de folhas e a morfologia e anatomia geral das plantas, sendo uma das mais utilizadas nas aulas o Catharanthus roseus (L.) Don. de acordo com Araújo (2011) essa relação aluno-natureza é de grande importância para a aprendizagem, pois além de motivar os alunos, as aulas práticas despertam a curiosidade e facilitam o contato com o desenvolvimento de um trabalho científico, e assim o aluno se torna mais participativo nas aulas e adquire mais subsídios para utilização do que aprendeu e produziu, e ainda aprende a conservar e preservas as espécies ornamentais.

Nessa perspectiva, é importante conservar as espécies ornamentais, pois além de trazerem harmonia e beleza para a UNEB campus II, ainda serve de instrumento para o aprendizado, já que são utilizadas em sala aulas de botânica e pesquisa de graduação.

\section{CONCLUSÃO}

Existe um bom quantitativo de espécies ornamentais pertencentes a família Apocynaceae no Campus II da UNEB, essas plantas ajudam a compor um bom cenário de harmonia e beleza trazendo a sensação de bem estar à comunidade acadêmica, e propõem a amenização do clima local do Campus. No entanto, outra demanda desses vegetais com potencial ornamental é a sua utilização em aulas práticas de botânica e pesquisas no curso de graduação de Ciências Biológicas. Portanto, faz-se necessária a manutenção dessas espécies para que futuras pesquisas sejam desenvolvidas, e para que continuem sendo fonte de conhecimento e embelezamento nos ambientes.

\section{REFERÊNCIAS}

ARAÚJO, R. C. M. S.; NASCIMENTO, A. P. Aulas práticas de Botânica contribuindo para formação do ensino de Ciências Biológicas. In: COLÓQUIO INTERNACIONAL: EDUCAÇÃO E CONTEMPORANEIDADE, 5, São Cristovão-SE, Anais... 2011.

JUDD, W. S. et al. Sistemática Vegetal: um enfoque filogenético. 3 ed., Porto Alegre, Artmed, 2009.

LORENZI, H.; SOUZA, H. M. Plantas ornamentais do Brasil (arbustivas herbáceas e trepadeiras). 3 ed. Nova Odessa, São Paulo: Ed. Plantarum, p.1088-1099,2001.

MELO, A. G. C.; CARVALHO, D. A.; CASTRO, G. C.; MACHADO, E. L. M. Fragmentos florestais urbanos. Revista Científica Eletrônica de Engenharia Florestal, v. 17, n. 1, p. 5879, 2011.

MELLO FILHO, L. E. Plantas ornamentais em paisagismo. ENCONTRO NACIONAL SOBRE FLORICULTURA E PLANTAS ORNAMENTAIS. Anais... 1986.

RAPINI, A. Sistemática: estudos em Asclepiadoideae (Apocynaceae) da Cadeia do Espinhaço de Minas Gerais. São Paulo: 2000. Instituto de Biociências, Universidade de São Paulo, 2000. (Tese de doutorado). Disponível em: <http://www.teses.usp.br/teses/disponiveis/41/41132/tde12122001-085018/>. Acesso em: 29 jan. 2016. 
RIZZINI, C. T.; MORS, W. B. Botânica econômica brasileira. 2 ed. Rio de Janeiro: Âmbito Cultural, 1995.

SALATINO, A. Nós e as plantas: ontem e hoje. Revista Brasileira de Botânica, v. 24, n. 4, p. 483-490, 2001.

SEI - Superintendência de Estudos Econômicos e Sociais da Bahia. Estatística dos municípios baianos. Salvador: SEI, 2010. v. 1.

SILVA, L. C. Plantas ornamentais tóxicas presentes no shopping Riverside Walkem TeresinaPI. Revsbau, v. 4, n. 3, p. 64-85, 2009. 